\title{
ANALISIS DAN PEMODELAN DISTRIBUSI TEGANGAN SUMUR BOR INJEKSI PADA PROSES UNDERGROUND COAL GASIFICATION
}

\author{
Analysis and Modelling of Stress Distribution on Injection Wellbore \\ under Underground Coal Gasification Process
}

\author{
IRFAN NAUFAL FAUZI ${ }^{{ }^{*}}$ dan ZULFAHMI ${ }^{2 *}$ \\ 1 Teknik Geologi - Universitas Pembangunan Nasional "Veteran" Yogyakarta \\ Jalan SWK Jalan Ring Road Utara No.104, Ngropoh, Condongcatur, Kec. Depok, \\ Kabupaten Sleman, Daerah Istimewa Yogyakarta 55283 \\ e-mail : Irfaninf28@gmail.com \\ 2 Puslitbang Teknologi Mineral dan Batubara \\ Jalan Jenderal Sudirman 623 Bandung 40211 \\ Telp. (022) 6030483, Fax. (022) 6003373 \\ * Kontributor Utama
}

\begin{abstract}
ABSTRAK
Gasifikasi batubara bawah tanah adalah proses gasifikasi batubara secara in-situ pada lapisan batubara yang jauh di bawah tanah dengan cara melakukan injeksi udara bertekanan melalui sumur bor dan menghasilkan gas bakar batubara melalui sumur produksi. Salah satu permasalahan yang perlu diperhatikan dalam proses gasifikasi ini adalah kerusakan konstruksi sumur bor pada saat menginjeksikan udara bertekanan ke dalam sumur, ketika akan membuat jalur koneksi antara sumur injeksi dan produksi. Beberapa faktor yang perlu dievaluasi adalah tegangan dan regangan maksimum, distribusi tegangan dan regangan dan distribusi temperatur di sekitar lokasi sumur tersebut. Analisis dan pemodelan geomekanika dilakukan terhadap kondisi di sekitar sumur bor injeksi dengan memerhatikan kekuatan dan ketebalan casing, karakteristik batuan, kekuatan dan daya lekat penyemenan yang merupakan pengontrol rusak atau tidaknya sumur bor tersebut. Dengan asumsi nilai faktor keamanan $\geq 1,3$, tegangan horizontal maksimum yang aman adalah $30 \mathrm{MPa}$ dengan perolehan nilai tegangan maksimum di sekitar lubang bor sebesar 454,07 MPa, tegangan minimum 0,476 MPa dan regangan maksimum sebesar $0,08 \mathrm{~m}$, serta distribusi temperatur berkisar antara $272,84-22^{\circ} \mathrm{C}$ dengan nilai terbesar di tengah lubang bor. Dengan demikian udara bertekanan maksimum yang diizinkan melalui konstruksi sumur injeksi adalah sebesar $30 \mathrm{MPa}$.
\end{abstract}

Kata kunci: gasifikasi batubara bawah tanah, kerusakan sumur bor, distribusi tegangan dan regangan, tegangan dan regangan maksimum dan minimum, faktor keamanan

\begin{abstract}
Underground coal gasification is the process of in-situ gasification of coal at the deep coal layer by injecting compressed air through a borehole and producing coal-fired gas through production wells. One of the problems that need to be considered in this gasification process is the damage to the construction of the borehole, when it injects compressed air into the well when making a connection line between the injection well and production. Several factors that need to be evaluated are the maximum stress and strain, stress and strain distribution and temperature distribution around the wellbore location. Geomechanical analysis and modeling are carried out on the conditions around the injection borehole by taking into account the strength and thickness of the casing, rock characteristics, strength and adhesion of cementing, which control whether the drill well is damaged or not. With the assumption that the value of the safety factor is $\geq 1$. 3 , the maximum horizontal stress
\end{abstract}


is $30 \mathrm{MPa}$ with the maximum stress value around the wellbore $454.07 \mathrm{MPa}$, minimum stress $0.476 \mathrm{MPa}$ and a maximum strain $0.0800 \mathrm{~m}$. The temperature distribution around the construction is $272.84-22{ }^{\circ} \mathrm{C}$ with the largest value in the middle of the borehole. Thus, the compressed air allowed through injection well construction is a maximum of $30 \mathrm{MPa}$.

Keywords: underground coal gasification, wellbore collapse, stress distribution, maximum strain, maximum and minimum stress, safety factor

\section{PENDAHULUAN}

Untuk menghasilkan energi bersih dan ramah lingkungan dari batubara, perlu dilakukan terobosan dan inovasi agar pemanfaatan batubara bisa lebih optimal. Hal ini sejalan dengan Peraturan Pemerintah Nomor 5 Tahun 2006 bahwa batubara diharapkan mempunyai kontribusi pada bauran energi nasional sebesar $33 \%$ pada 2025. Tidak semua cadangan batubara dapat dieksploitasi secara konvensional, baik dengan tambang terbuka maupun bawah tanah (Zulfahmi dan Huda, 2014). Berdasarkan perhitungan sumber daya batubara, jumlah batubara Indonesia sebanyak 161 miliar ton dan bila dieksploitasi dengan tingkat produksi saat ini, akan mencukupi kebutuhan sampai 150200 tahun. Sekitar 120 miliar ton batubara dapat ditambang secara terbuka (open pit) dan sisanya menggunakan metode tambang bawah tanah (Badan Geologi, 2014).

Underground coal gasification (UCG) atau gasifikasi batubara bawah tanah adalah proses gasifikasi secara in-situ yang memanfaatkan batubara tidak ekonomis untuk ditambang, baik secara terbuka maupun bawah tanah (Zulfahmi, 2017). UCG dapat mengonversi batubara in-situ menjadi produk gas, umumnya dikenal sebagai gas sintesis atau syngas. Gasifikasi mengubah hidrokarbon menjadi syngas pada suhu dan tekanan tinggi serta dapat digunakan untuk berbagai produk lain seperti listrik, bahan baku kimia, bahan bakar cair dan hidrogen (Burton $d k k$., 2004).

Pada saat proses gasifikasi, stabilitas konstruksi sumur bor, baik injeksi maupun produksi sangat penting untuk dijaga agar keberlangsungan produksi injeksi udara pada saat membuat jalur koneksi dan pembakaran batubara tetap terpelihara. Masalah stabilitas lubang sumur menjadi perhatian serius, karena melibatkan banyak faktor, terutama stabilitas konstruksi, teknik pengeboran, teknik penyemenan dan injeksi udara bertekanan (Charlez dan Onaisi, 2001 dalam Chatterjee, Singha dan Sangvai, 2013).
Pada saat proses pengeboran, pembesaran lubang bor merupakan konsekuensi jangka panjang yang harus siap dihadapi, akibat kondisi peralatan yang kurang baik, tekanan formasi dan lumpur yang tidak seimbang, sehingga menyebabkan banyaknya runtuhan dinding sumur bor yang menyumbat annulus yang mengakibatkan pipa bor terjepit. Demikian juga proses penyemenan yang kurang baik dapat menyebabkan lemahnya konstruksi sumur (Last, 2001 dalam Chatterjee, Singha dan Sangvai, 2013).

Batuan dalam keadaan alami mengalami tegangan dalam tiga arah utama: tegangan vertikal (Sv) dan dua tegangan horizontal, yaitu tegangan horizontal maksimum $(\mathrm{SH})$ dan minimum (sh). Saat proses pengeboran, lumpur bor berfungsi sebagai pengganti dan penahan distribusi tegangan batuan. Namun karena lumpur bor berupa fluida dan tekanan lumpur pengeboran yang seragam, hal ini tidak dapat secara tepat menyeimbangkan tegangan alamiah. Akibatnya, batuan yang mengelilingi lubang sumur mengalami deformasi dan sering mengalami kegagalan akibat tekanan yang didistribusikan melebihi kekuatan batuan (Ask, 2007).

Kegagalan ini dapat berupa kegagalan tarik (tensile failure), yang terjadi ketika lumpur bor bertekanan tinggi, namun tegangan batuan melebihi kekuatan tarik. Selain itu dapat terjadi kegagalan tekan (compressive failure), akibat tekanan lumpur yang rendah dan tegangan batuan melebihi kuat tekan, sehingga menyebabkan terjadinya borehole breakout, yaitu peristiwa pecahnya lubang bor secara vertikal, sehingga terjadi pembesaran lubang bor (Bell dan Gough, 1979). Kondisi ini muncul ketika konsentrasi tegangan di sekitar lubang bor melebihi kekuatan batuan (Barton, Zoback dan Burns, 1988). Bentuk breakout terjadi pada sisi berlawanan dengan sisi lubang bor yang sejajar tegangan horizontal minimum (sh). 
Distribusi tegangan yang tinggi di sekitar lubang sumur, menyebabkan membesarnya lubang melebihi kekuatan batuan yang ada di sekitarnya. Ketika hal ini terjadi akan berakibat batuan di sekitar lubang sumur hancur dan sumur bor pun akan rusak atau retak-retak akibat beban tegangan tersebut (Barton, Zoback dan Burns, 1988).

Ambruknya lubang bor merupakan masalah yang sangat serius dalam proses injeksi udara bertekanan pada proses UCG, karena proses injeksi ini bisa menyebabkan tertahannya udara di sekitar sumur bor. Akibatnya, tegangan di sekitar lubang bor bisa naik ke atas dan mencari bidang lemah, sehingga bisa menyebabkan kebocoran konstruksi sumur. Kerusakan yang terjadi di sekitar sumur injeksi akan berakibat fatal dan sangat berbahaya. Perbaikan terhadap kondisi sumur seperti ini akan menambah biaya dan menghambat proses UCG.

Beberapa faktor yang perlu diperhatikan mencakup tegangan in-situ, besaran tegangan utama, arah dan tekanan fluida serta kondisi porositas batuan. Oleh karena itu diperlukan studi untuk menganalisis distribusi tegangan pada sumur bor injeksinya yang bertujuan untuk mengetahui: tegangan maksimal dan tegangan minimal sumur bor injeksi, regangan maksimal dan regangan minimal sumur bor injeksi UCG.

Beberapa penelitian tentang kondisi tegangan insitu di sekitar sumur pada umumnya terkait dengan kondisi normal atau kondisi sumur pada batuan keras seperti yang dilakukan oleh Bell dan Gough (1979), Barton, Zoback dan Burns (1988), Ewy (1999), Chatterjee dan Mukhopadhyay (2003), Chatterjee, Singha dan Sangvai (2013), Lian, Shi dan Han (2014), Bengbeng dan Yanghua (2017), Albukhari dkk. (2018) dan Han $d k k$. (2019). Tulisan ini membahas pemodelan tentang kondisi sumur bor injeksi pada kegiatan UCG.

\section{METODE}

Metode penelitian yang digunakan yaitu mengevaluasi data karakteristik material penyusun konstruksi sumur bor, antara lain karakteristik selubung baja (casing) yang digunakan, kekuatan dan daya lekat semen dan karakteristik batuan di sekitar lokasi pengeboran. Data diperoleh dari hasil penelitian sebelumnya berupa karakteristik geomekanika lapisan batuan di lokasi yang menjadi target penelitian, data karakteristik semen yang digunakan serta spesifikasi teknis casing yang diperoleh dari data fabrikasi. Data sekunder tersebut berasal dari hasil penelitian yang telah dilakukan oleh beberapa peneliti di Puslitbang Teknologi Mineral dan Batubara. Selain itu, data primer juga digunakan dari hasil pengamatan langsung di laboratorium. Analisis dan pemodelan 3D telah dilakukan dengan pengolahan data menggunakan Metode Elemen Hingga (MEH). Perangkat lunak yang digunakan adalah Ansys berlisensi dengan beberapa interpretasi serta adjustment dari penulis. Hasil perhitungan dan pemodelan akan diperoleh nilai distribusi tegangan dan regangan serta kondisi temperatur di sekitar lubang bor injeksi.

\section{Pengolahan Data}

MEH tergolong metode numerik yang memiliki kemampuan yang lebih baik dibandingkan dengan metode konvensional dalam hal perhitungan tegangan dan pergerakan massa tanah. Metode ini secara umum mampu memodelkan berbagai kondisi yang kompleks dengan baik, seperti perilaku teganganregangan tidak linier, kondisi-kondisi tidak homogen dan perubahan geometri selama konstruksi timbunan. MEH dapat digunakan untuk menganalisis suatu struktur agar dapat diketahui nilai pendekatan tegangan. Kata "struktur" mempunyai pengertian semua benda yang dikenai suatu beban atau pengaruhpengaruh lainnya. Pengaruh-pengaruh tersebut akan menyebabkan terjadinya deformasi (regangan) pada rangkaiannya juga disertai dengan terjadinya tegangan dalam dan reaksi pada titik tertahan (Fish dan Belytschko, 2007).

Pada suatu analisis $\mathrm{MEH}$, daerah yang akan dianalisis dibagi menjadi beberapa elemen yang tersambungkan pada titik-titik nodal (Gambar 1 dan 2). Metode ini memungkinkan perhitungan kondisi tegangan secara lengkap pada masingmasing elemen serta deformasi arah horizontal dan vertikal pada titik-titik nodal setiap tahapan analisis. 


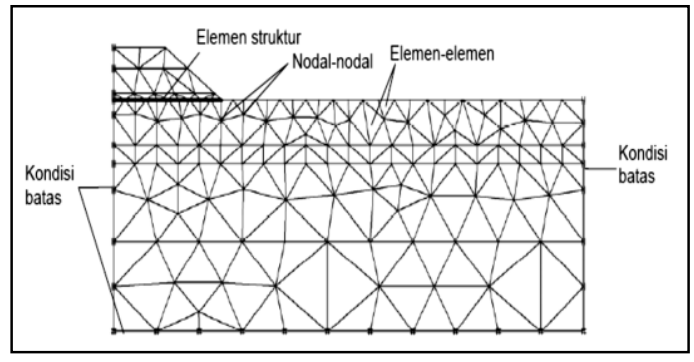

Gambar 1. Jaring (mesh) pada analisis MEH (Fish dan Belytschko, 2007)

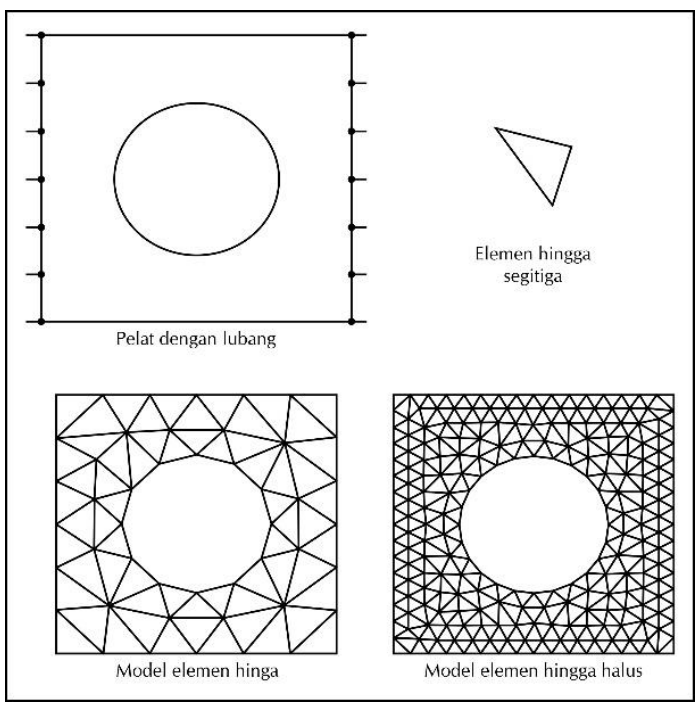

Gambar 2. Model jaring pada pelat (Fish dan Belytschko, 2007)

Beberapa peneliti seperti Bellarby (2009), Wan (2011) dan Byrom (2014) menjelaskan bahwa Faktor Keamanan suatu sumur sama dengan Design Factor (DF) konstruksi pipa selubung, yaitu perbandingan antara Pipe Rating (rating pipa selubung) dengan Expected Load (beban sumur bor). Pada tulisan ini beban sumur bor merupakan akumulasi tensile loads, burst loads, collapse loads, axial loads dan tri-axial loads, sedangkan cementing loads diasumsikan sama dengan kekuatan selubung.

\section{Asumsi Data}

Model yang digunakan dalam penelitian ini yaitu geometri lapisan batuan/formasi sebesar $10 \mathrm{~m}$ dari diameter casing, dengan kedalaman $250 \mathrm{~m}$ di bawah permukaan tanah. Ketebalan annulus sebesar 76,2 mm, ketebalan concrete sebesar 53,34 mm, dengan tipe casing K-55 steel berdiameter 7 inci, dan ketebalan 8,05 mm (Gambar 3).

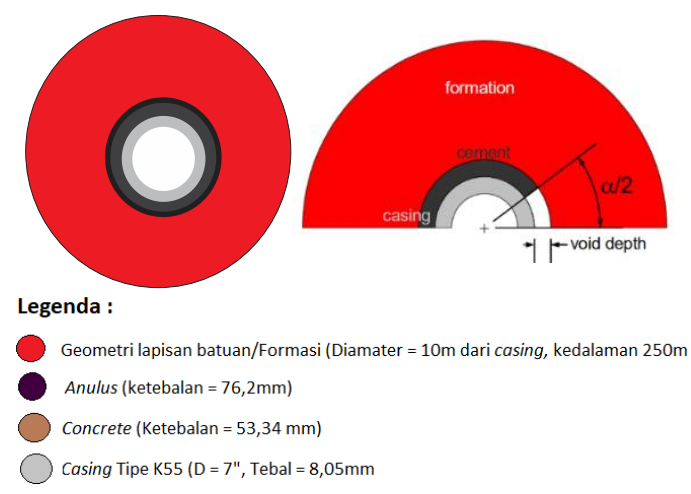

Gambar 3. Model geometri

Pada Tabel 1, jenis litologi batuan yang dibuat sebagai model pada penelitian ini terdiri dari tiga jenis batuan atau perlapisan, yaitu batubara, batulumpur, dan batupasir yang mempunyai karakteristik berbeda.

Dari ketiga lapisan batuan tersebut telah dilakukan uji sifat mekanika batuan di Puslitbang tekMIRA sebelum pemodelan ini dilakukan. Ada 4 parameter uji, yaitu Uniaxial Compression, Brazillian, Direct Shear dan Triaxial test seperti yang diperlihatkan pada Tabel 2.

Tabel 3 memperlihatkan data sifat mekanik selubung baja (casing) tipe $\mathrm{K}-55$ yang digunakan sebagai material pelindung untuk laju aliran udara bertekanan yang akan diinjeksikan ke dalam formasi batubara.

Tabel 1. Sifat fisik batuan

\begin{tabular}{llccccccc}
\hline \multirow{2}{*}{ No } & \multirow{2}{*}{ Lithology } & $\mathrm{pn}$ & $\mathrm{pd}$ & $\mathrm{ps}$ & $\mathrm{W}$ & $\mathrm{S}$ & $\mathrm{n}$ & \multirow{2}{*}{$\mathrm{e}$} \\
\cline { 2 - 7 } & $\mathrm{gr} / \mathrm{cm}^{3}$ & $\mathrm{gr} / \mathrm{cm}^{3}$ & $\mathrm{gr} / \mathrm{cm}^{3}$ & $\%$ & $\%$ & $\%$ & \\
\hline 1 & Coal & 1,33 & 1,28 & 1,35 & 3,48 & 66,67 & 6,7 & 0,07 \\
2 & Mudstone & 2,11 & 2,06 & 2,144 & 2,478 & 61,214 & 8,356 & 0,09 \\
3 & Sandstone & 2,262 & 2,178 & 2,354 & 3,882 & 45,598 & 17,7 & 0,218 \\
\hline
\end{tabular}


Tabel 2. Sifat mekanik batuan

\begin{tabular}{|c|c|c|c|c|c|c|}
\hline \multirow[b]{2}{*}{ Lithology } & \multicolumn{6}{|c|}{ UCS } \\
\hline & $\begin{array}{l}\text { App Dencity } \\
\text { (g/cc) }\end{array}$ & $\begin{array}{l}\text { Max. Load } \\
(\mathrm{kN})\end{array}$ & $\begin{array}{c}\mathrm{E} \\
(\mathrm{Mpa})\end{array}$ & poisson & $\begin{array}{l}\text { UCS } \\
\text { (Mpa) }\end{array}$ & $\begin{array}{c}\mathrm{NPI} \\
(\mathrm{N} / \mathrm{mm})\end{array}$ \\
\hline Coal & 1,2325 & 27,662 & 916,035 & 0,3375 & 9,48 & 24,42 \\
\hline Mudstone & 2,278 & 7,62 & 247,608 & 0,346 & 2,734 & 13,66 \\
\hline Sandstone & 2,304 & 12,284 & 630,826 & 0,364 & 0,364 & 17,73 \\
\hline \multirow[b]{2}{*}{ Lithology } & \multicolumn{6}{|c|}{ Brazilian } \\
\hline & $\begin{array}{l}\text { Wet } \\
\text { (g/cc) }\end{array}$ & \multicolumn{3}{|c|}{$\begin{array}{l}\text { Tensile Deformation Modulus } \\
\text { (Mpa) }\end{array}$} & \multicolumn{2}{|c|}{$\begin{array}{l}\text { Tensile Strength } \\
\text { (Mpa) }\end{array}$} \\
\hline Coal & 1,225 & \multicolumn{2}{|c|}{164,87} & & \multicolumn{2}{|c|}{0,94} \\
\hline Mudstone & 1,55 & \multicolumn{2}{|c|}{49,31} & & \multicolumn{2}{|c|}{0,46} \\
\hline Sandstone & - & \multicolumn{2}{|c|}{-} & & \multicolumn{2}{|c|}{0,3} \\
\hline \multirow[b]{2}{*}{ Lithology } & \multicolumn{6}{|c|}{ Direct Shear } \\
\hline & $\begin{array}{l}\text { C peak } \\
(\mathrm{Mpa})\end{array}$ & $\begin{array}{c}\phi \text { peak } \\
\text { (degree) }\end{array}$ & $\begin{array}{l}\text { C residu } \\
\text { (Mpa) }\end{array}$ & & $\begin{array}{l}\phi \text { residu } \\
\text { (degree) }\end{array}$ & NPI \\
\hline Coal & 1,15 & 29,28 & 0,42 & & 20,732 & 24 \\
\hline Mudstone & 0,903 & 22,29 & 0,29 & & 16,64 & 10 \\
\hline Sandstone & 1,167 & 23,72 & 0,32 & & 17,71 & 31 \\
\hline \multirow{2}{*}{ Lithology } & \multicolumn{6}{|c|}{ Triaxial } \\
\hline & \multicolumn{2}{|c|}{ Cohesion (Mpa) } & \multicolumn{4}{|c|}{ Internal Friction Angle, $\phi$ (degree) } \\
\hline Coal & \multicolumn{2}{|c|}{2,04} & \multicolumn{4}{|c|}{39,49} \\
\hline Mudstone & \multicolumn{2}{|c|}{1,135} & \multicolumn{4}{|c|}{9,475} \\
\hline Sandstone & \multicolumn{2}{|c|}{1,56} & \multicolumn{4}{|c|}{17,84} \\
\hline
\end{tabular}

Tabel 3. Data mekanik baja Casing K-55 (Canada steel and casing import Inc.)

\begin{tabular}{lr}
\hline Mechanical properties Casing K-55 Steel & \\
\hline Type/ Grade & K-55 \\
Size & 7 inch \\
Nominal Weight $(\mathrm{Kg} / \mathrm{m})$ & 34,23 \\
Outer Diameter $(\mathrm{mm})$ & 177,8 \\
Wall Thickness $(\mathrm{mm})$ & 8,05 \\
Tensile Strength (Mpa) & 655 \\
Min. Yield Strength (MPa) & 379 \\
Max. Yield Strength (Mpa) & 552 \\
\hline
\end{tabular}

Tabel 4 menunjukkan parameter yang digunakan dalam penelitian ini. Tabel ini juga menyertakan material penyemenan (concrete cementing) sebagai data tambahan untuk melihat model distribusi tegangan pada konstruksi sumur yang akan dibuat.

Dalam penelitian ini pemodelan numerik tegangan di sekitar wellbore dilakukan secara 3D dengan area $10 \times 10 \mathrm{~m}^{2}$ dan diameter casing sebesar 7 inci dengan ketebalan casing sebesar $8,05 \mathrm{~mm}$. Simulasi perubahan tegangan horizontal maksimum digunakan untuk melihat distribusi tegangan dan temperatur di sekitar lubang bor. Variasi tegangan horizontal maksimum dalam simulasi ini, yaitu:

1. $\mathrm{SH}=10 \mathrm{Mpa}$ 7. $\mathrm{SH}=26 \mathrm{MPa}$

2. $\mathrm{SH}=14 \mathrm{Mpa}$ 8. $\mathrm{SH}=28 \mathrm{MPa}$

3. $\mathrm{SH}=16 \mathrm{Mpa}$ 9. $\mathrm{SH}=30 \mathrm{MPa}$

4. $\mathrm{SH}=18 \mathrm{Mpa}$ 10. $\mathrm{SH}=40 \mathrm{MPa}$

5. $\mathrm{SH}=22 \mathrm{Mpa}$ 11. $\mathrm{SH}=50 \mathrm{MPa}$

6. $\mathrm{SH}=24 \mathrm{Mpa}$ 12. $\mathrm{SH}=70 \mathrm{MPa}$

Tabel 4. Karakteristik sifat baja K-55 dan material penyemenan (Lian, Shi dan Han, 2014)

\begin{tabular}{lrr}
\hline \multicolumn{3}{c}{ Material Properties Steel \& Concrete } \\
\hline Material Properties & Steel & Concrete \\
Young Modulus (GPa) & 205 & 2,79 \\
Poisson's Ratio & 0,3 & 0,15 \\
Density $\left(\mathrm{Kg} / \mathrm{m}^{3}\right)$ & 7850 & 1666 \\
Th. Conductivity $\left(\mathrm{W} /\left(\mathrm{m}^{\circ} \mathrm{C}\right)\right)$ & 46 & 0,81 \\
Specific Heat $\left(\mathrm{kJ} / \mathrm{kg}^{\circ} \mathrm{C}\right)$ & 0,49 & 0,88 \\
Thermal Expansion $\left(1 /{ }^{\circ} \mathrm{C}\right)$ & 0,000012 & 0,000009 \\
Compressive Strength $(\mathrm{MPa})$ & - & 27,6 \\
Coefficient of Friction & & 552 \\
Max Shear Stress (MPa) & & 0,72 \\
\hline
\end{tabular}




\section{Formulasi Persamaan}

1) Regangan.

Didefinisikan sebagai perbandingan antara pertambahan panjang dengan panjang awalnya. Pertambahan panjang ini tidak hanya terjadi pada ujungnya saja, tetapi pada setiap bagian batang yang terentang dengan perbandingan yang sama. Atau bisa dikatakan bahwa regangan merupakan besarnya deformasi dibandingkan dengan kondisi awalnya (Rai, Kramadibrata dan Wattimena, 2012).

$$
\mathrm{e}=\frac{\Delta \mathrm{l}}{\mathrm{I}_{0}}
$$

2) Tegangan.

Tegangan didefinisikan sebagai perbandingan antara gaya tarik yang dikerjakan pada benda dengan luas penampangnya atau tegangan merupakan besarnya gaya yang dialami suatu luasan batuan. Apabila gaya yang bekerja tegak lurus terhadap permukaan, tegangan yang demikian disebut tegangan normal (normal stress), sedangkan gaya yang bekerja sejajar dengan permukaan dikatakan sebagai tegangan geser (shear stress) (Rai, Kramadibrata dan Wattimena, 2012).

3) Modulus Young.

$$
\sigma=\frac{F}{A}
$$

Modulus elastisitas didefinisikan sebagai perbandingan antara tegangan dengan regangan suatu bahan selama gaya yang bekerja tidak melampaui batas elastisitasnya.

$$
\begin{gathered}
\mathrm{E}=\Delta \sigma \Delta \varepsilon a \\
\varepsilon=\Delta l l \times 100 \%
\end{gathered}
$$

dengan:

$\mathrm{E} \quad$ : Modulus young (MPa)

$\Delta \sigma$ : Perbedaan tegangan aksial (MPa)

$\Delta \varepsilon a$ : Perbedaan regangan aksial (\%)

$\Delta \mathrm{l}$ : Perubahan panjang percontoh batuan uji (mm)

4) Nisbah Poisson (Poisson Ratio).

Nisbah Poisson didefinisikan sebagai perbandingan negatif antara regangan lateral dan regangan aksial. Nisbah Poisson menunjukkan adanya pemanjangan ke arah lateral (lateral expansion) akibat adanya tegangan dalam arah aksial.

$$
v=\varepsilon l \varepsilon a
$$

dengan:

$\mathrm{v}$ : Nisbah Poisson

$\varepsilon$ l : Regangan lateral $(\mathrm{mm})$

عa : Regangan aksial $(\mathrm{mm})$

\section{HASIL DAN PEMBAHASAN}

\section{Hasil}

Pemodelan numerik ini berbasis $\mathrm{MEH}$ menggunakan Software Ansys Workbench, Static Structural. Pada Gambar 4 diperlihatkan salah satu contoh hasil iterasi terhadap beban $\mathrm{SH}=10 \mathrm{MPa}$ yang menunjukkan hasil tegangan maksimal sebesar $1,4479 \times 10^{8} \mathrm{~Pa}$, yang ditandai warna merah dan tegangan minimum sebesar $2,81487 \times 10^{5}$ Pa ditandai warna biru.

Nilai regangan maksimum diperoleh sebesar 0,026809 seperti diperlihatkan pada Gambar 5. Bila beban seperti ini, berdasarkan analisis faktor keamanan diperoleh angka minimum sebesar 4,5236; (Gambar 6).

Menurut Beath $d k k$. (2004), permasalahan utama kegagalan yang terjadi pada awal uji coba di Soviet adalah akibat tekanan, pergerakan tanah dan suhu tinggi. Seiring dengan pengetahuan tentang kondisi tegangan yang dipengaruhi beban thermal dan semen grouting, tingkat kegagalan sumur pada UCG sudah jarang terjadi. Tabel 4 menunjukkan hasil simulasi 12 variasi tegangan horizontal maksimum yang dipengaruhi oleh beban termal pada georeaktor UCG terhadap nilai distribusi tegangan maksimum dan minimum, regangan serta nilai faktor keamanan.

Model distribusi tegangan diperlihatkan pada Gambar 7 yang menunjukkan nilai-nilai tegangan utama maksimum, menengah dan minimum.

Menurut Seifi (2014), meskipun kondisi temperatur di sekitar selubung dipengaruhi oleh temperatur Georeaktor UCG yang bisa mencapai sampai $1200^{\circ} \mathrm{C}$, namun kondisi temperatur pada selubung sumur injeksi sangat signifikan dipengaruhi oleh kondisi lapisan yang dilalui dan injeksi udara yang dialirkan. Bahkan menurut Kostúr, Laciak dan Durdan (2018), temperatur lapisan batuan yang berada lebih dari $5 \mathrm{~m}$ dari batas lapisan batubara yang terbakar, ternyata sudah mengalami penurunan temperatur yang drastis. Meskipun demikian, pada iterasi model distribusi temperatur pada penelitian ini, masih menunjukkan angka maksimum $272,84^{\circ}$ pada casing di sekitar batubara seperti diperlihatkan pada Gambar 8 . 

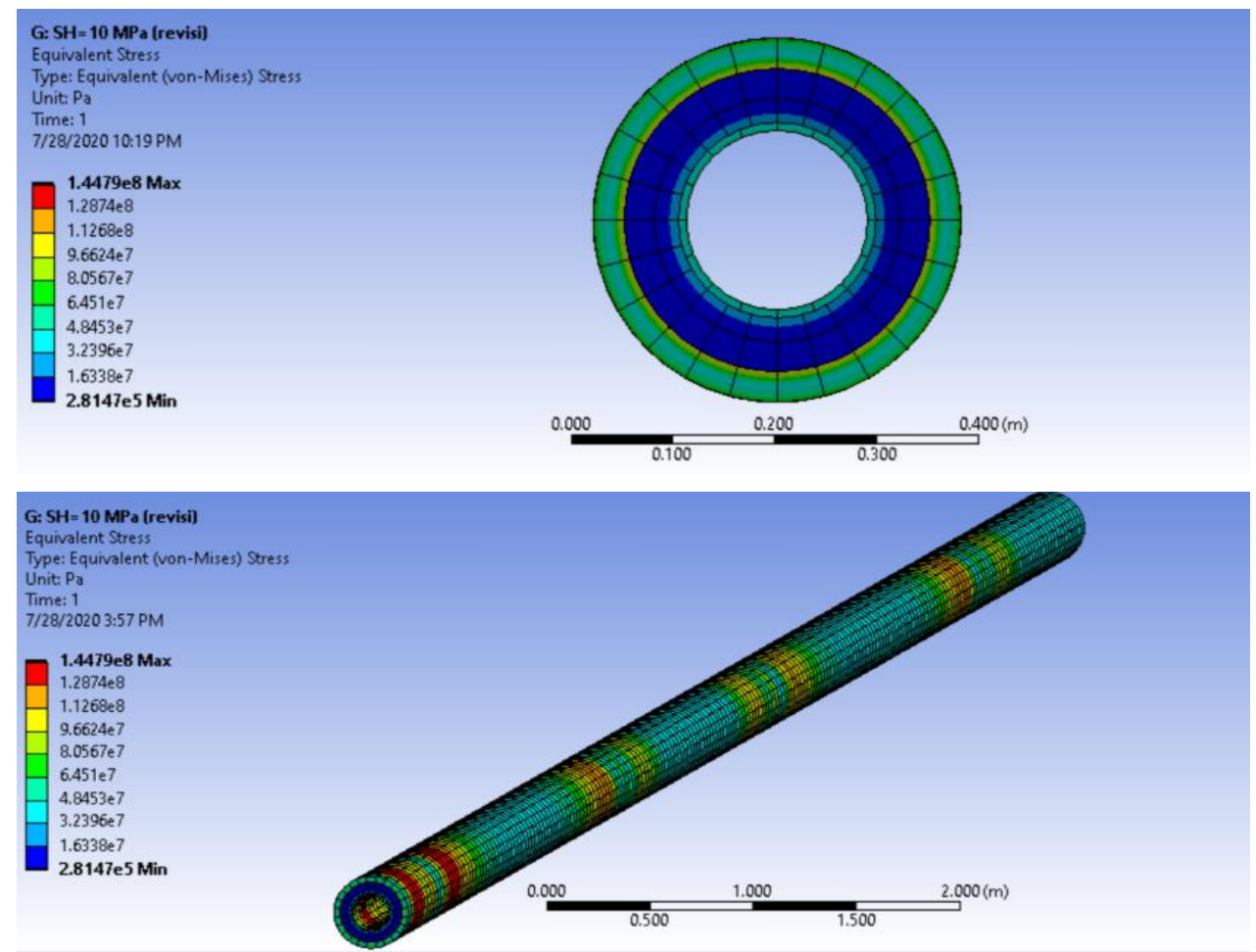

Gambar 4. Equivalent (von-misses) stress

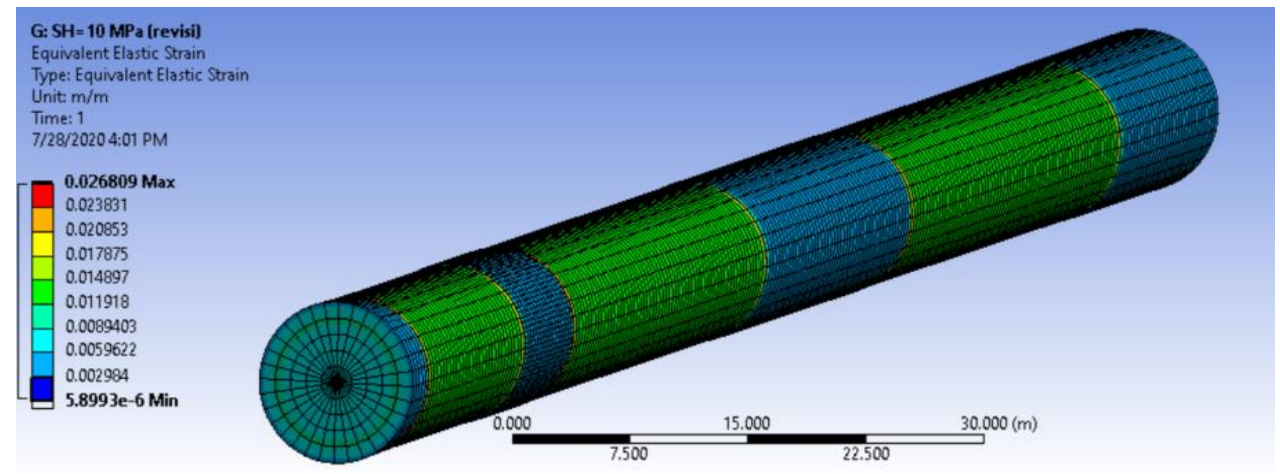

Gambar 5. Equivalent elastic strain

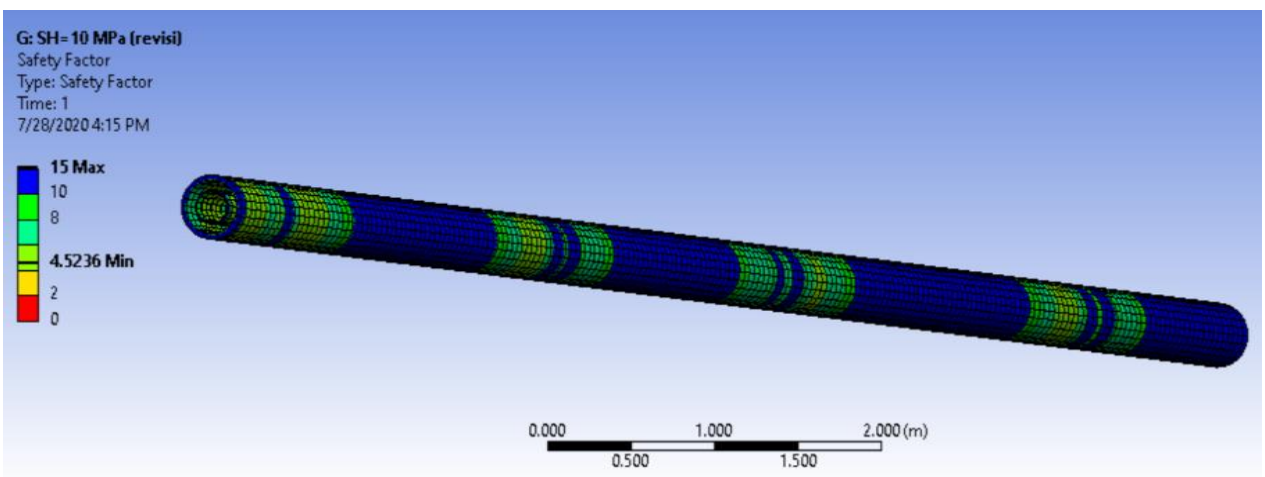

Gambar 6. Faktor keamanan 
Tabel 4. Hasil simulasi variasi tegangan horizontal maksimum (SH)

\begin{tabular}{ccccc}
\hline $\begin{array}{c}\text { Tegangan Horizontal } \\
(\mathrm{Mpa})\end{array}$ & $\begin{array}{c}\text { Tegangan Maksimum } \\
(\mathrm{MPa})\end{array}$ & $\begin{array}{c}\text { Tegangan Minimum } \\
(\mathrm{Mpa})\end{array}$ & Regangan Max $(\mathrm{m})$ & Safety Factor \\
\hline $\mathbf{1 0}$ & 144,79 & 0,28147 & 0,0268 & 4,52 \\
$\mathbf{1 4}$ & 207,70 & 0,49819 & 0,0380 & 3,15 \\
$\mathbf{1 6}$ & 239,70 & 0,54776 & 0,0435 & 2,73 \\
$\mathbf{1 8}$ & 217,30 & 0,59017 & 0,0491 & 2,41 \\
$\mathbf{2 2}$ & 332,83 & 0,27181 & 0,0601 & 1,97 \\
$\mathbf{2 4}$ & 363,31 & 0,16274 & 0,0638 & 1,80 \\
$\mathbf{2 6}$ & 393,94 & 0,43644 & 0,0692 & 1,66 \\
$\mathbf{2 8}$ & 424,39 & 0,25664 & 0,0746 & 1,54 \\
$\mathbf{3 0}$ & 454,07 & 0,47604 & 0,0800 & 1,44 \\
$\mathbf{3 4}$ & 509,66 & 0,80095 & 0,0907 & 1,29 \\
$\mathbf{3 6}$ & 539,39 & 0,98625 & 0,0962 & 1,21 \\
$\mathbf{3 8}$ & 569,08 & 0,10209 & 0,1017 & 1,15 \\
$\mathbf{4 0}$ & 598,68 & 0,10599 & 0,1073 & 1,09 \\
$\mathbf{5 0}$ & 746,01 & 0,12898 & 0,1349 & 0,88 \\
$\mathbf{7 0}$ & 1039,5 & 0,92422 & 0,1902 & 0,63 \\
\hline
\end{tabular}

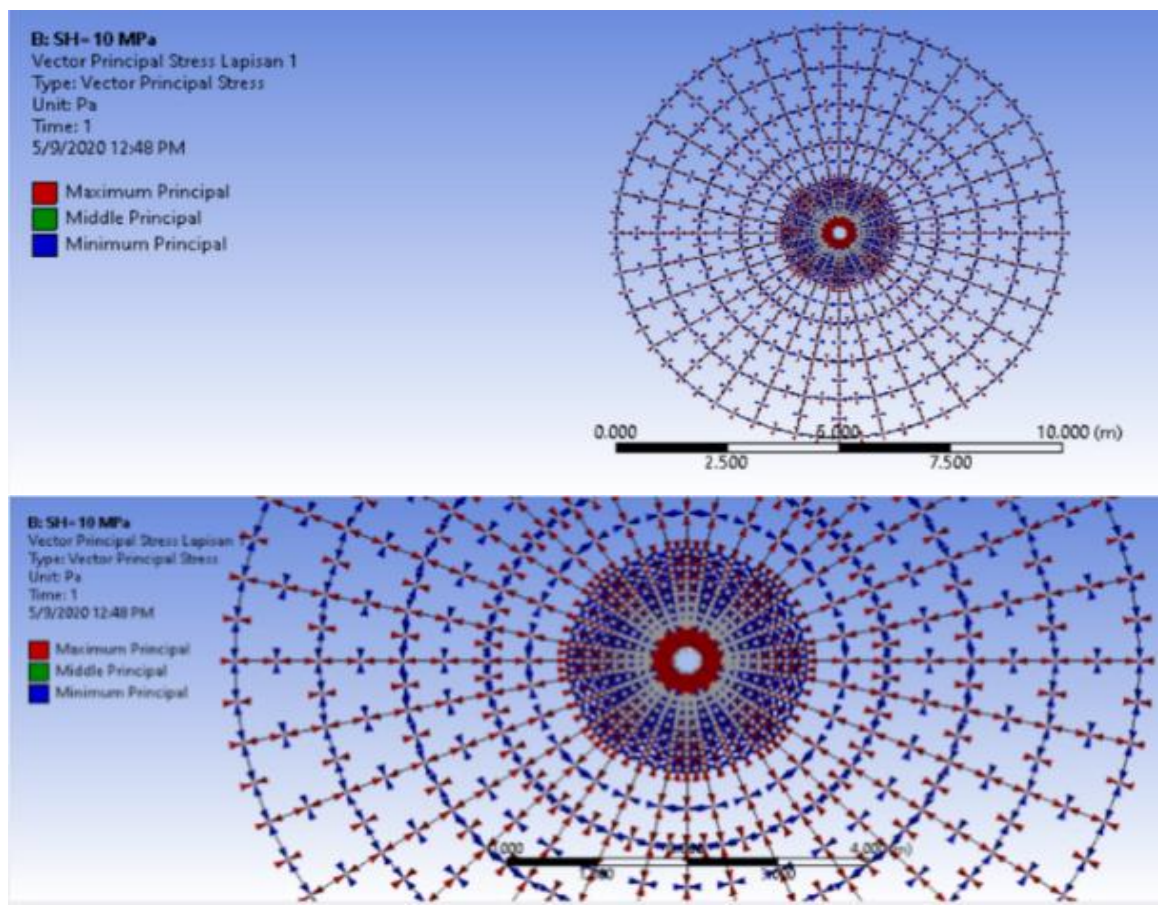

Gambar 7. Distribusi tegangan

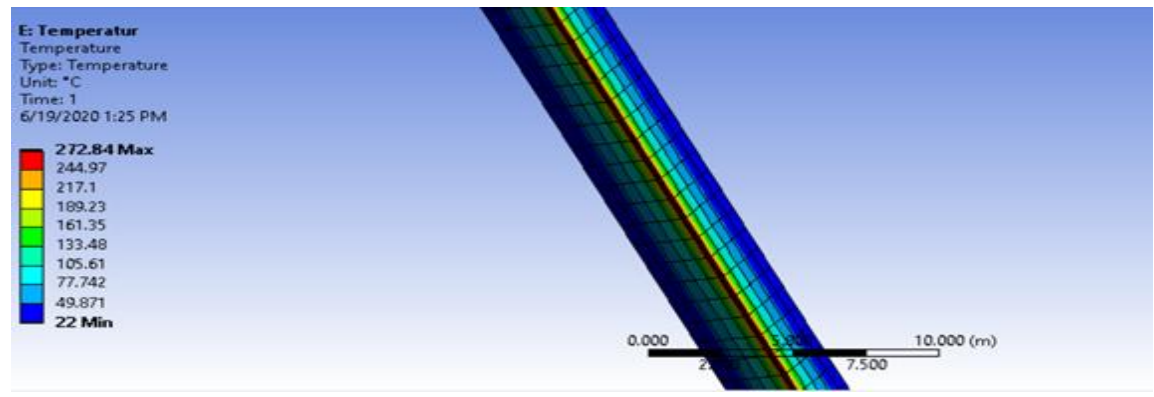

Gambar 8. Distribusi temperatur 


\section{Pembahasan}

Untuk menganalisis kondisi lubang bor, data sifat mekanik formasi seperti Nisbah Poisson dan Modulus Young sangat penting untuk diperhatikan (Albukhari $d k k ., 2018$ ). Pada penelitian ini data tersebut diperoleh dari uji laboratorium. Parameter geomekanika terkait erat dengan kriteria yang dikembangkan oleh beberapa ahli (Han $d k k ., 2019$ ). Kekuatan struktur batuan dalam analisis deformasi batuan dinilai dengan menggunakan beberapa kriteria keruntuhan seperti kriteria keruntuhan Hoek-Brown (Hoek dan Brown, 2019).

Kriteria ini banyak digunakan dalam perhitungan pemodelan pada beberapa perangkat lunak yang dikeluarkan oleh Itasca. Kriteria Hoek-Brown untuk analisis ini dalam bentuk nonlinier dalam ruang tegangan mayor dan minor, sehingga kekuatan kohesif dan sudut gesekan yang setara berbeda pada tingkat tegangan yang berbeda. Kriteria keruntuhan Hoek-Brown ini direpresentasikan dalam rumus (Han $d k k ., 2019)$ :

$$
\sigma_{1}^{\prime}=\sigma_{3}^{\prime} N_{\phi}+2 c \sqrt{N_{\phi}}=\sigma_{3}^{\prime} N_{\phi}+U C S
$$

$\mathrm{N}_{\phi}=\frac{1+\sin \phi}{1-\sin \phi^{\prime}} ; \phi=$ sudut gesek dalam; $\mathrm{c}=$ kohesi; $\sigma_{1}{ }^{\prime}$ dan $\sigma_{3}{ }^{\prime},=$ tegangan utama mayor dan minor efektif serta UCS = Kuat tekan uniaksial.

Kriteria keruntuhan Modified Lade (Ewy, 1999) yang sering dipakai untuk simulasi ditribusi tegangan pada dinding lubang bor. Kriteria modified Lade direpresentasikan dalam rumus (Ewy, 1999):

$$
\frac{\left(l_{1}^{\prime \prime}\right)^{3}}{l_{3}^{\prime \prime}}=27+n_{L}
$$

Nilai $I_{1}{ }^{\prime \prime}=\sigma_{1}{ }^{\prime}+\sigma_{2}{ }^{\prime}+\sigma_{3}{ }^{\prime}+3 S_{L}$ dan $I_{3}{ }^{\prime \prime}=\left(\sigma_{1}{ }^{\prime}+S_{L}\right)$ $\left(\sigma_{2}{ }^{\prime}+\mathrm{S}_{\mathrm{L}}\right)\left(\sigma_{3^{\prime}}{ }^{\prime}+\mathrm{S}_{\mathrm{L}}\right) ; \mathrm{S}_{\mathrm{L}}$ dan $\eta \mathrm{L}$ adalah kekuatan yang berhubungan dengan konstanta material.

Kriteria keruntuhan Drucker-Prager dan von Mises yang banyak digunakan dalam analisis deformasi pada perangkat lunak Ansys. Ansys mengkombinasikan kriteria Mohr-coulomb, von Mises dan Drucker-Prager dalam analisis pemodelan. Ketiga kriteria keruntuhan tersebut diformulasikan dalam beberapa rumus (Boldyrev dan Muyzemnek, 2008; Sica, 2017; Han dkk., 2019), yaitu:
Mohr-coulomb:

$$
\sigma_{1}=\sigma_{3} \frac{1+\sin \phi}{1-\sin \phi}+\frac{2 c \cos \phi}{1-\sin \phi}
$$

von Mises (Sica, 2017):

$$
\frac{1}{2}\left[\left(\sigma_{1}-\sigma_{2}\right)^{2}+\left(\sigma_{2}-\sigma_{3}\right)^{2}+\left(\sigma_{3}-\sigma_{1}\right)^{2}\right] \leq \sigma_{y}^{2}
$$

Drucker-Prager:

$$
\begin{gathered}
\sigma_{y}=\frac{6 c \cos (\phi)}{3^{1 / 2}(3-\sin (\phi))} ; \beta=\frac{2 \sin (\phi)}{\sqrt{3(3-\sin (\phi))}} \\
c=\frac{3^{1 / 2 \sigma_{y}(3-\sin (\phi))}}{6 \cos (\phi)} \pi r^{2}
\end{gathered}
$$

Nilai c adalah kekuatan kohesi dan $\phi$ adalah sudut gesek dalam. Formulasi dari beberapa kriteria tersebut menjadi dasar dalam perhitungan deformasi batuan dan kondisi struktur lubang bor, ketika diberi beban tekanan kompresi melalui kompresi udara tekan.

Tabel 4 dan beberapa grafik hasil simulasi menunjukkan bahwa ada kecenderungan peningkatan tegangan dan regangan maksimum ketika tegangan horizontal meningkat, seperti yang diperlihatkan pada grafik pada Gambar 9 dan 11. Sedangkan tegangan horizontal yang meningkat tidak signifikan memengaruhi perubahan tegangan minimum (Gambar 10).

Selaras dengan penelitian yang dilakukan oleh Chatterjee dan Mukhopadhyay (2003) dan Chatterjee, Singha dan Sangvai (2013) bahwa hasil prediksi model bergantung pada sifat elastis batuan, geometri model dan kondisi batas. Berbeda dengan penelitian Chatterjee, Singha dan Sangvai (2013) yang umumnya pada batuan keras, model yang digunakan pada penelitian ini berada pada batuan lunak, sehingga tegangan yang diberikan tidak terlalu besar. Hasil simulasi faktor keamanan minimum yang dapat diterima adalah sebesar $40 \mathrm{MPa}$ dengan nilai $\mathrm{SF}=1,09$. Gambar 12 menunjukkan grafik hasil simulasi tegangan horizontal terhadap nilai faktor keamanan. Bila dilihat dari distribusi tegangan seperti pada Gambar 7, tegangan maksimum terdistribusi pada bagian bidang lemah yang berada pada dinding sumur.

Bila dilihat dari distribusi tegangan seperti pada Gambar 7, tegangan maksimum terdistribusi pada bagian bidang lemah yang berada di dinding sumur. Oleh karena itu, penggunaan selubung baja dan konstruksi penyemenan 
yang tahan temperatur tinggi dan tahan tekanan dan apabila mengacu pada faktor keamanan $>1,3$, maksimum tekanan adalah 30 Mpa. Pembatasan tekanan ini sangat diperlukan agar kegiatan operasional pengeboran dan proses UCG dapat berlangsung dengan aman.

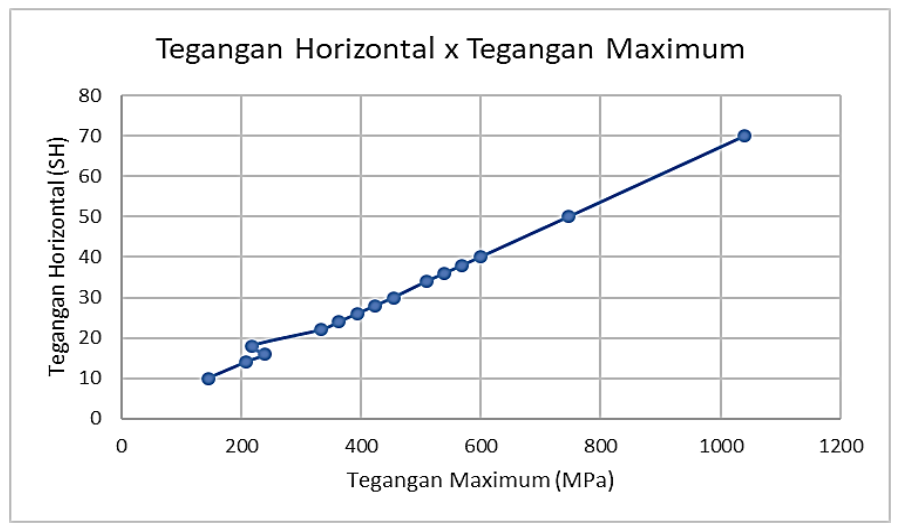

Gambar 9. Grafik tegangan horizontal terhadap tegangan maximum

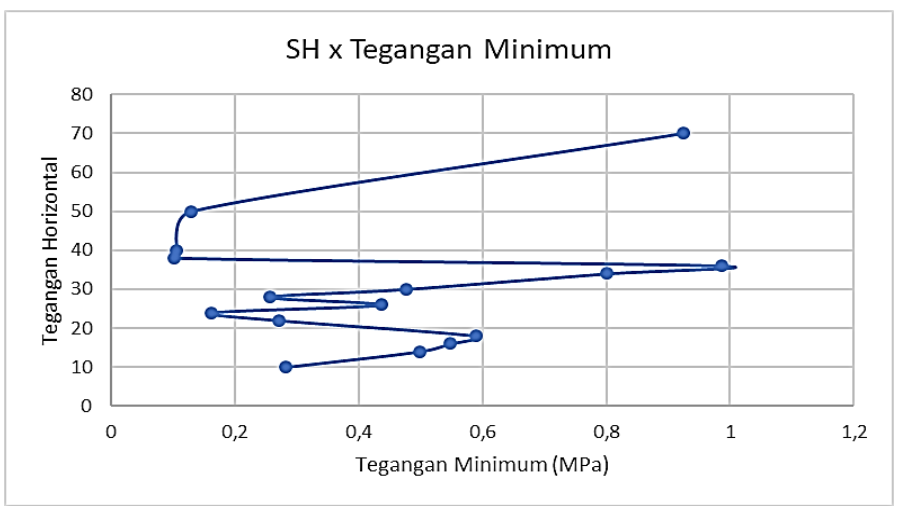

Gambar 10. Grafik tegangan horizontal terhadap tegangan minimum

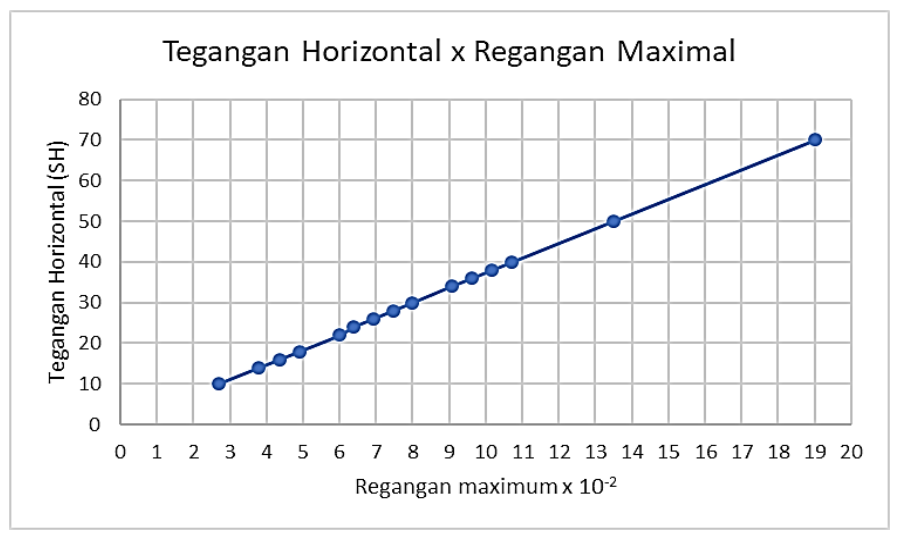

Gambar 11. Grafik tegangan horizontal terhadap regangan maksimum 


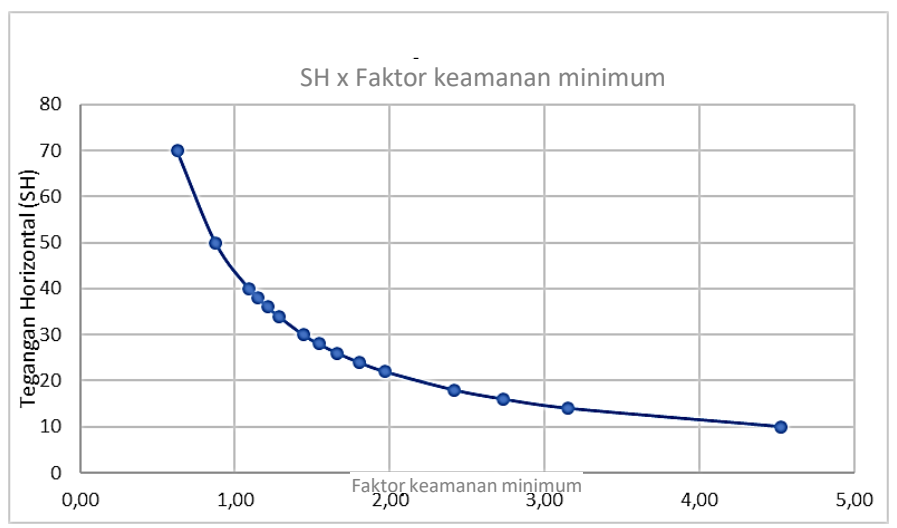

Gambar 12. Grafik tegangan horizontal terhadap faktor keamanan minimum

\section{KESIMPULAN DAN SARAN}

\section{Kesimpulan}

Perpindahan resultan gaya dan distribusi tegangan pada model menunjukkan variasi yang seragam di sepanjang batas lubang sumur dengan tegangan maksimum mengarah pada dinding sumur. Pada kondisi batas tegangan dan regangan yang melebihi nilai keamanan, deformasi terjadi dan diameter lubang sumur berkurang di semua sisi. Lubang sumur menjadi elips dengan sumbu panjangnya berorientasi ke arah SH. Kontur tegangan Von Mises menunjukkan variasi tegangan yang seragam yang berlaku di sekitar lubang sumur. Vektor tegangan menunjukkan redistribusi arah tegangan horizontal di sekitar lubang sumur. Pada simulasi diperlihatkan bahwa model dengan tegangan horizontal yang lebih kecil atau sama dengan $30 \mathrm{MPa}$ masih aman dari kerusakan sumur, tegangan $40 \mathrm{MPa}$ adalah kondisi kritis dan pada kondisi tegangan $>40$ MPa akan berbahaya untuk kekuatan konstruksi sumur. Apabila diaplikasikan dalam proses UCG, tekanan kompresi udara $\leq 30 \mathrm{MPa}$ di lokasi telitian masih aman terhadap konstruksi sumur bor injeksi.

\section{Saran}

Pemutakhiran data geomekanika setiap lapisan batuan dengan perlapisan yang sesuai dengan kondisi sebenarnya, data sifat fisik dan mekanik selubung baja dan semen concrete sangat diperlukan untuk menjamin kesesuaian pemodelan dengan hasil yang sebenarnya. Skala pemodelan yang sesuai dalam Ansys sangat menentukan akurasi hasil pemodelan.

\section{UCAPAN TERIMA KASIH}

Ucapan terima kasih kepada rekan-rekan di Laboratorium Geomekanika Puslitbang Teknologi Mineral dan Batubara (tekMIRA) dan segenap jajaran pimpinan tekMIRA yang telah memberikan kesempatan dalam melakukan penelitian ini.

\section{DAFTAR PUSTAKA}

Albukhari, T. M., Beshish, G. K., Abouzbeda, M. M. dan Madi, A. (2018) "Geomechanical wellbore stability analysis for the reservoir section in J-NC186 oil field," in 1st International Conference on Advances in Rock Mechanics - TuniRock 2018. Hammamet, Tunisia: International Society for Rock Mechanics and Rock Engineering, hal. ISRMTUNIROCK-2018-22.

Ask, D. (2007) "Evaluation of overcoring stress measurements in boreholes KFM01B, DBT-1 and DBT-3 and hydraulic stress measurements in boreholes KFM01A, KFM01B, KFM02A and KFM04A at the Forsmark site," in Forsmark site investigation. Svensk Kärnbränslehantering $\mathrm{AB}$, hal. 1-86.

Badan Geologi (2014) Pemutakhiran data sumber daya energi status 2014. Bandung.

Barton, C. A., Zoback, M. D. dan Burns, K. L. (1988) "In-situ stress orientation and magnitude at the Fenton Geothermal Site, New Mexico, determined from wellbore breakouts," Geophysical Research Letters, 15(5), hal. 467470. doi: 10.1029/GL015i005p00467.

Beath, A., Craig, S., Littleboy, A., Mark, R. dan Mallett, C. (2004) Underground coal 
gasification: Evaluation environmental barriers. Queensland, Australia: CSIRO.

Bell, J. S. dan Gough, D. I. (1979) "Northeastsouthwest compressive stress in Alberta evidence from oil wells," Earth and Planetary Science Letters, 45(2), hal. 475-482. doi: 10.1016/0012-821X(79)90146-8.

Bellarby, J. (2009) "Well completion design, Volume 56," in Developments in Petroleum Science. 1 ed. Elsevier Science, hal. 726.

Bengbeng, Z. dan Yanghua, C. (2017) "Study on stress distribution of casing under different elliptical combinations," Scholars Journal of Engineering and Technology, 5(5), hal. 197202.

Boldyrev, G. G. dan Muyzemnek, A. J. (2008) "The modeling of deformation process in soils with use of ansys and Ls-Dyna programs," in 6th International Conference on Case Histories in Geotechnical Engineering. Missouri University of Science and Technology, hal. 1.08 (1-10).

Burton, E. A., Upadhye, R., Friedmann, S. J., Leif, R., McNab, W., Knauss, K., Ezzedine, S. dan Smith, J. R. (2004) Assessment of UCG site locations. Livermore, California.

Byrom, T. G. (2014) Casing and liners for drilling and completion: Design and application. 2 ed. Gulf Professional Publishing.

Chatterjee, R. dan Mukhopadhyay, M. (2003) "Numerical modelling of stress around a wellbore," in SPE Asia Pacific Oil and Gas Conference and Exhibition. Society of Petroleum Engineers. doi: 10.2118/80489-MS.

Chatterjee, R., Singha, D. K. dan Sangvai, P. (2013) "Deformation modeling around a wellbore using finite element technique," in 10thBiennial International Conference \& Exposition. India: SPG India, hal. P 199.

Ewy, R. T. (1999) "Wellbore-stability predictions by use of a modified lade criterion," SPE Drilling \& Completion, 14(02), hal. 85-91. doi: 10.2118/56862-PA.
Fish, J. dan Belytschko, T. (2007) A first course in finite elements. 1st Ed. New York: Wiley.

Han, Y., Liu, C., Phan, D., AlRuwaili, K. dan Abousleiman, Y. (2019) "Advanced wellbore stability analysis for drilling naturally fractured rocks," in SPE Middle East Oil and Gas Show and Conference. Manama, Bahrain: Society of Petroleum Engineers, hal. SPE-195021-MS. doi: 10.2118/195021-MS.

Hoek, E. dan Brown, E. T. (2019) "The hoek-Brown failure criterion and GSI - 2018 edition," Journal of Rock Mechanics and Geotechnical Engineering, 11(3), hal. 445-463. doi: 10.1016/j.jrmge.2018.08.001.

Kostúr, K., Laciak, M. dan Durdan, M. (2018) “Some influences of underground coal gasification on the environment," Sustainability, 10(5), hal. 1512. doi: 10.3390/su10051512.

Lian, Z., Shi, T. dan Han, J. R. (2014) Thermal-stress simulation of a casing in a heavy-oil recovery well. China: China National Science Foundation (Project No, 50074025).

Rai, M. A., Kramadibrata, S. dan Wattimena, R. K. (2012) Mekanika batuan. Bandung: ITB Press.

Seifi, M. (2014) Simulation and modeling of underground coal gasification using porous medium approach. University of Calgary.

Sica, L. U. R. (2017) An experimental study of the validity of the von Mises yielding criterion for elasto-viscoplastic materials. Pontificia Universidade Católica.

Wan, R. (2011) Advanced well completion engineering. Gulf Professional Publishing.

Zulfahmi (2017) Model kekuatan batuan pengapit batubara sebagai respon termal pada proses underground coal gasification (UCG): Studi kasus batuan dari formasi Muara Enim Cekungan Sumatera Selatan. Universitas Padjadjaran.

Zulfahmi dan Huda, M. (2014) Pengembangan aplikasi teknologi underground coal gasification (UCG) di Indonesia tahap 1. Bandung: Puslitbang tekMIRA. 